\title{
Community-integrated brain injury rehabilitation: Treatment models and challenges for civilian, military, and veteran populations
}

\author{
Tina M. Trudel, PhD; ${ }^{*}$ F. Don Nidiffer, PhD; Jeffrey T. Barth, PhD \\ Defense and Veterans Brain Injury Center at Virginia NeuroCare, Lakeview Healthcare Systems, University of \\ Virginia Medical School, Charlottesville, VA
}

\begin{abstract}
Traumatic brain injury (TBI) is a major health problem in civilian, military, and veteran populations. Individuals experiencing moderate to severe TBI require a continuum of care involving acute hospitalization and postacute rehabilitation, including community reintegration and, one would hope, a return home to function as a productive member of the community. In the military, the goal is to help individuals with TBI return to active duty or make an optimal return to civilian life if the extent of their injuries necessitates a "medical board" discharge. Whether civilian, military, or veteran with TBI, individuals who move beyond the need to live in a facility must be reintegrated back into the community. This article discusses four treatment models for community reintegration, reviews treatment standardization and outcome issues, and describes a manualized rehabilitation pilot program designed to provide community reintegration and return to duty/work for civilians, veterans, and military personnel with TBI.
\end{abstract}

Key words: brain injury, cognitive rehabilitation, communityintegrated rehabilitation, community integration, community reentry, Defense and Veterans Brain Injury Center, functional rehabilitation, home-based rehabilitation, neurobehavioral rehabilitation, treatment manuals.

\section{INTRODUCTION}

Traumatic brain injury (TBI) has become a leading public health problem for civilians and the military. In the U.S. civilian population, 1.4 million individuals sustain TBI annually, resulting in 235,000 hospital admissions and 50,000 deaths [1]. Economically, the total impact of direct and indirect medical and other costs in 1995 dollars is reported to exceed $\$ 56$ billion [2]. The Centers for Disease Control and Prevention estimate that long-term disability as a result of brain injuries (necessitating assistance with activities of daily living) affects 5.3 million Americans, with thousands more affected every year [3].

Brain injury has always been a possible consequence of military duty. The frequency of TBI in the military and the need to develop new medical technologies to address the efficiency of evolving warfare have been instrumental in encouraging research and advancement of clinical care for TBI [4]. Recognition of the unique challenges of TBI in the military and the need to provide effective treatment approaches contributed to the development of the Defense and Veterans Brain Injury Center (DVBIC), established in 1992 (formerly known as the Defense and Veterans Head Injury Program). The DVBIC provides an

\footnotetext{
Abbreviations: $\mathrm{CBT}=$ cognitive-behavioral therapy, $\mathrm{CIR}=$ community-integrated rehabilitation, DVBIC $=$ Defense and Veterans Brain Injury Center, ICF $=$ International Classification of Functioning, Disability and Health, IED = improvised explosive device, OIF $=$ Operation Iraqi Freedom, PTSD $=$ posttraumatic stress disorder, $\mathrm{RCT}=$ randomized controlled trial, $\mathrm{TBI}=$ traumatic brain injury, $\mathrm{VANC}=$ Virginia NeuroCare, $\mathrm{WHO}=$ World Health Organization.

*Address all correspondence to Tina M. Trudel, PhD; Defense and Veterans Brain Injury Center at Virginia NeuroCare, 1101-B East High Street, Charlottesville, VA 22902; 603-493-4946; fax: 603-539-8888. Email: ttrudel@lakeview.ws DOI: $10.1682 / J R R D .2006 .12 .0167$
} 
integrated program to enhance clinical quality, research, and education across the military and veteran TBI treatment continuum, including community-integrated brain injury rehabilitation through its civilian partner, Virginia NeuroCare (VANC).

The professional and public focus on TBI in the military has dramatically increased with the rise of brain injuries in Operation Iraqi Freedom (OIF) and Operation Enduring Freedom in Afghanistan. With regard to OIF, the Office of the Surgeon General of the Army notes that 64 percent of wounded-in-action injuries are the result of blasts from improvised explosive devices (IEDs), rocketpropelled grenades, land mines, or mortar/artillery shells [5]. Given the improvements in protective helmets and the resultant reductions in penetrating head trauma, closed-head blast injuries have become the signature injury of these military operations [5].

Many individuals who sustain TBI in military and civilian settings are treated and return to active duty, productive work and social roles, family responsibilities, and their premorbid lifestyle. However, some TBI survivors live with residual disability, have unmet care needs, or are initially unsuccessful in reentering home, military, vocational, and community life. Those TBI survivors at risk for unsatisfactory outcomes or with continued rehabilitation needs are candidates for community-integrated rehabilitation (CIR).

CIR is a broad term that encompasses various approaches and contexts (hospital, neurobehavioral facility, residential setting, home, and day programs) for treatment, supported by a gradually evolving body of observational and scientific evidence. Military personnel and veterans receiving CIR services through DVBIC and programs such as VANC will provide us with practical data for the continued development of a variety of postacute rehabilitation services [6].

\section{APPROACHES TO COMMUNITY-INTEGRATED REHABILITATION}

CIR is one facet of postacute brain injury rehabilitation and generally includes a number of approaches that allow individuals with TBI to benefit from further rehabilitation after medical stability is established and initial acute (in-hospital) rehabilitation is completed. Typically, CIR does not include subacute brain injury rehabilitation programs that specialize in coma management or the treatment of behaviors that actively pose a risk of serious endangerment [7]. The most common delineation of CIR programs has followed the framework proposed by Malec and Basford [7], including neurobehavioral programs, residential programs, comprehensive holistic (day treatment) programs, and home-based programs [6-9] (Table).

Neurobehavioral CIR programs have historically focused on treatment of mood, behavior, and executive function disorders, while ensuring supervision and safety in a residential, nonhospital setting. These programs focus on psychosocial outcomes, emphasizing application of behavioral principles and development of functional skills. Neurobehavioral CIR programs typically have interdisciplinary treatment teams (multiple professional disciplines involved in the development and implementation of coor-

Table.

Delineation of community-integrated rehabilitation models.

\begin{tabular}{lll}
\hline \multicolumn{1}{c}{ Model } & \multicolumn{1}{c}{ Participant Characteristics } & \multicolumn{1}{c}{ Description } \\
\hline Neurobehavioral & $\begin{array}{l}\text { Severe behavioral disturbances, require } \\
\text { 24-hour supervision. }\end{array}$ & $\begin{array}{l}\text { Residential setting, intensive behavioral } \\
\text { management. } \\
\text { Residential Community }\end{array}$ \\
$\begin{array}{l}\text { Cannot participate as outpatients, require } \\
\text { 24-hour supervision or support. }\end{array}$ & $\begin{array}{l}\text { Residential setting with full community } \\
\text { integration, comprehensive clinical team } \\
\text { treatment. }\end{array}$ \\
Comprehensive Holistic & $\begin{array}{l}\text { Need for intensive services, benefit from } \\
\text { improved awareness. }\end{array}$ & $\begin{array}{l}\text { Day treatment programs, integrated, } \\
\text { multimodal rehabilitation. }\end{array}$ \\
Home-Based Program & $\begin{array}{l}\text { Able to reside at home, able to self-direct } \\
\text { care. }\end{array}$ & $\begin{array}{l}\text { Education and advisement, telephonic } \\
\text { and Web-based support and services, } \\
\text { home-based therapeutic activity, availability } \\
\text { of outpatient supplemental services, highly } \\
\text { variable. }\end{array}$ \\
\hline
\end{tabular}


dinated care), include direct support personnel as therapeutic extenders, and are often led by neuropsychologists or behavior analysts [9].

Residential CIR programs were initially developed for individuals who not only required extended comprehensive TBI rehabilitation but also required 24-hour supervision or did not have access to adequate outpatient/day services. The homelike environment and staff support the skill development needed to negotiate everyday life, easing generalization across community environments.

A recent attempt to quantify the characteristics of residential CIR programs demonstrated a blurring line between such programs and neurobehavioral CIR programs or assisted-living facilities. A recent survey of residential CIR programs demonstrated the broad scope and acuity of this level of care, with 47 percent of participants using wheelchairs, 35 percent incontinent, 23 percent described as assaultive, and 63 percent identified as having severe TBI. Programs were highly variable in length of stay (0.13-288 months), staff-to-participant ratio (0.77-3.3), time from injury to admission (0.2180 months), participants with no expectation of improvement $(0 \%-50 \%)$, participants involved in nonprogram therapeutic activities $(0 \%-100 \%)$, and amount of time involved in these activities (1.5-40 hours). As a result, the term "residential CIR" is virtually meaningless compared with earlier operational definitions and provides no standardized treatment elements [7-8,10].

Comprehensive holistic day-treatment CIR programs provide a milieu-oriented, multimodal approach with a neuropsychological focus. Interventions target awareness, cognitive functions, social skills, and vocational preparation through individual, group, and familyinvolved interventions delivered by an interdisciplinary team [11]. These programs are among the most studied in the entire field of CIR, and while treatment guidelines are often site-specific, these programs are important facets of the rehabilitation continuum, providing observation, assessment, and dissemination of treatment techniques and intervention strategies [7,11-13].

Home-based CIR programs involve a highly variable degree of services and supports for the individual with TBI who is able to reside in a home environment. Typically, such individuals do not require 24-hour supports or supervision. Home-based CIR may include the spectrum of outpatient services commonly accessed through individual treatment providers, clinics, or minimal professional supports. Usually no identified "treatment team" exists, although collaboration across a number of health and social service systems may be evident [14]. Behavioral approaches using self-monitoring and cueing are employed, as well as models wherein family members or in-home paraprofessionals are engaged as therapeutic change agents. Additionally, home-based CIR involves participant education and the growing use of telephonic, Web-based, and technological aides [6,8].

\section{EFFICACY OF COMMUNITY-INTEGRATED REHABILTATION}

\section{Community-Integrated Rehabilitation Program Outcome Overview}

Community integration is typically identified as a desirable CIR outcome, although the construct has proven difficult to define and measure, because of lack of correlation between key community integration measures and measures of problem behavior or quality of life [1516]. Measures of CIR outcome often include individual goal attainment, functional abilities, vocational status, psychological status, cognitive functioning, subjective feelings of well-being, burden of care/resource needs, and items from the World Health Organization (WHO) International Classification of Functioning, Disability and Health (ICF) activity and participation domains (previously referred to as disability and handicap), which include health condition, bodily functions and structure, participation, activities, environment, and personal factors and their interactions [15,17-18].

A recent Cochrane review of multidisciplinary rehabilitation summarizes that limited evidence exists for the effectiveness of "community-based multidisciplinary rehabilitation" [19]. Improvement in functional outcome on the level of WHO-ICF "activity" has been noted, but little support has been found for easing the burden of caregivers. The review excludes numerous CIR observational studies on methodological grounds, highlighting the need for further quality research and randomized controlled trials (RCTs) in this area [19]. The precursor to RCTs, development of standardized CIR treatment manuals, is also lacking in the literature.

The applied behavior analysis literature provides innumerable descriptions of neurobehavioral interventions, primarily analyzed through single-subject experimental designs. A thorough review article by Wood et al., addressing the postacute neurobehavioral CIR program 
literature, describes the difficulties of outcome analysis related to the blurring of program labels, categories, and definitions, while also pointing to positive observational outcome findings among severely injured survivors of TBI [9]. Primary positive outcomes reported include reduced social dependency, lower cost of care, and reduced care hours; however, vocational outcome was called "disappointing" [9]. RCTs and standardized CIR treatment manuals are not found in the neurobehavioral CIR program review literature.

With the broad diversity previously noted among residential CIR programs, generalization and applicability of research findings are very limited. One study comparing residential CIR with home-based CIR programs that included matched controls (severe TBI) demonstrated greater functional improvement for the residential CIR group, although this improvement was not reflected in community integration scores [8]. Focused home-based CIR program studies have yielded mixed results. Implementation of behaviorally focused treatment through a home-based CIR model in one study by Carnevale et al. did not reduce caregiver burden in a small community sample [20], whereas Pace et al. found that a more interdisciplinary team-based model of intervention demonstrated a high rate of treatment outcome goals achieved and family/funder satisfaction [21]. In the latter study, no objective measures of functioning were reported and services provided were highly variable.

In another study of military personnel with TBI, Warden et al. found that participant outcomes from a self-directed home-based CIR model with participant education, instruction, and minimal professional involvement were comparable to those of participants served through a hospital-based cognitive rehabilitation program. Outcome measures of return to work; fitness for military duty; and cognitive, behavioral, and quality of life measures were similar between the home-based CIR and hospital-based cognitive rehabilitation groups. More detailed analyses of fitness for duty at 1 year indicated that the more severely injured participants fared better when treated in the hospital-based cognitive rehabilitation setting and the less severely injured participants fared better when treated at home [6].

Comprehensive holistic/day-treatment CIR programs demonstrate the strongest research foundation, with recent RCTs supporting their efficacy [16]. Early comprehensive CIR program studies date back almost two decades $[7,11]$ and more references are found in the liter- ature for this type of CIR program than any other. Unfortunately, most early studies are observational, without randomization or controls, and lack standardized approaches to treatment. In these early studies, comprehensive holistic/day-treatment CIR programs appear to produce gains that are maintained by most participants over time [22], increase societal participation [12], show better vocational outcomes [11], and improve self- and family ratings [23]. Effectiveness of the comprehensive holistic/day-treatment CIR program model appears to have cross-cultural relevance, with positive outcomes observed outside of the more common sites of the United Kingdom and the United States, including recent studies in Japan [24] and Finland [25].

In one of the few comprehensive holistic/day-treatment CIR studies with an RCT design, multidisciplinary community-based outreach and rehabilitation, compared with information only, was associated with significant improvement in level of functional activities, selforganization, and psychological well-being, as well as positive trends (without statistical significance) in personal care, mobility, and cognitive functions. No differential improvement was observed on measures of socialization, employment, anxiety, or depression [16]. Although most studies are observational, and randomization and controls are scarce, a body of evidence is growing that is based on pre- to postfunctional outcome assessments for treatment efficacy in the comprehensive holistic/day-treatment CIR program literature. Overall, functionally based rehabilitation in this day-treatment model shows promise to improve quality of life post-TBI.

\section{Community-Integrated Rehabilitation Programs and Severity of Injury}

Observational studies and matched-control designs demonstrate some benefits of CIR programs across the acuity continuum. The majority of individuals with mild TBI do not require comprehensive CIR, therefore few studies address this model. While not a comprehensive CIR study, Tiersky et al. found reduced anxiety and depression and improved cognitive functioning but no significant improvement in community integration scores in a randomized, wait list, control study of participants with mild TBI enrolled in a 3-day a week, 11-week long psychotherapy- and cognitive-remediation focused intervention model [26]. In another study by Cicerone et al., a mild-to-moderate TBI cohort demonstrated improved personal independence, neuropsychological test scores, 
and community integration following a comprehensive CIR program based on a holistic neuropsychological model compared with matched controls who received more typical outpatient rehabilitation. The comprehensive CIR program participants had greater improvement on measures of cognitive function and were twice as likely to demonstrate clinical benefit on a measure of community integration than the matched controls who received outpatient therapies [27].

CIR programs have some support in the moderate-tosevere TBI literature, including remediation of neurobehavioral problems [9] and higher productivity based on ratings of activities [25]. However, mixed results were noted in a study of predominantly moderate-to-severe TBI patients versus controls that compared specialized team CIR with an interdisciplinary model of TBI rehabilitation to existing services available in various community settings in the United Kingdom [28]. None of the outcome measures was statistically significant and evidence was lacking for the efficacy of either the interdisciplinary CIR model or the available community services compared with the control group [28].

\section{Timing of Community-Integrated Rehabilitation}

Compelling arguments for late CIR have been advanced from both neuroscience and clinical perspectives, including functional rehabilitation as a result of unmasking preexisting pathways and facilitating new relationships within and among neural networks [29]. Brain plasticity is viewed by many as a lifelong characteristic of the human brain, with the possibility of reorganization existing years after an injury. The literature regarding the "slow-to-recover" is well detailed elsewhere [30]. In the aforementioned comprehensive CIR program RCT, time since injury was unrelated to the magnitude of demonstrated gains [16].

Early research of comprehensive CIR programs used individuals with static conditions many years following their injury. These individuals served as their own controls and demonstrated improvement with comprehensive CIR [7]. Treating individuals with brain injuries that occurred more than a year before they received CIR is common throughout the CIR literature, particularly for individuals with more severe injuries. In a study by Malec, participants 4.6 years postinjury (on average) demonstrated social benefit from a comprehensive holistic/day-treatment CIR program, with a mean treatment duration of 189.5 days [12]. Overall neuropsychological functioning and community integration scores improved in another comprehensive CIR program (focusing on cognitive rehabilitation) in which patients were 33.9 months postinjury (on average) with a mean treatment duration of 3.8 months [27]. A study comparing groups with severe TBI entering a comprehensive CIR program within 6 months of injury, between 6 and 12 months after injury, and 12 months postinjury observed comparable gains in degree of disability, independence, home skills, and productivity across all three groups [31], further demonstrating the potential benefit from CIR during the extended postacute period.

\section{EVIDENCE-BASED TREATMENT ISSUES}

\section{Challenges of Randomized Controlled Trials}

The focus on RCTs as the "gold standard" raises significant ethical, scientific, and resource challenges in CIR research. While much of modern healthcare outside of CIR is also not supported by this gold standard, rehabilitation is particularly weak in its foundation, especially for CIR programs. The heterogeneity of CIR treatment models, lack of standardized treatment manuals, stages of treatment, time since injury, duration of treatment, context of services, goals/outcomes measured, and above all, the heterogeneity of TBI patients themselves, place significant burdens on research endeavors. The process of informed consent for individuals with cognitive impairments, many of whom may not be competent, also places limits on research. The length of time wherein the benefits of postacute rehabilitation may manifest themselves may be longer than the time most research grants fund or most researchers are able to endure. Additionally, RCTs are often plagued by small sample sizes due to recruitment challenges and availability of the defined TBI population for the CIR intervention being examined [32-33].

From an ethical standpoint, as increasing numbers of observational and methodologically weaker studies in TBI CIR provide an expanding body of evidence as to the benefit of treatment, no-treatment control groups, wait list controls, or standard (less effective) treatment control groups are increasingly difficult to justify. This ethical quandary is further compounded by the growing body of treatment evidence in related fields such as stroke rehabilitation. Additionally, even with developing TBI treatment RCTs and mounting observational evidence, such 
information is only effective when combined with the professional judgment and skill to make use of the research findings with any specific program participant [32-34].

Research in TBI CIR is restricted by the lack of available funding, limited numbers of trained personnel, and much of the treatment occurring outside the medical model and the more typically funded medical-research and university-hospital systems. The previously mentioned problems with definition and standardization may forestall successful grant applications and wider recognition in the research world. A number of these challenges in TBI research are well described in a recent DVBIC article examining multicenter research that compares cognitive-didactic versus functional-experiential treatment approaches, including implications of applicable standards of care that may evolve over the course of a study or extend across all groups of participants, including controls; access to adequate numbers of participants given inclusion/exclusion criteria; areas of theoretical and practical overlap in treatment comparison studies; and the general issues of time, effort, and expense [35].

Advancing knowledge regarding TBI CIR will require research models that systematically address various profiles of TBI (mild to severe, youth to elderly, etc.) and outcome goals of participants and clinicians, theoretical approaches and programmatic models, the treatment setting (hospital, CIR program types, in vivo), the timing of treatment and its variation by pattern of recovery and nature of injury, and the detailed well-defined methods through which interventions are provided and outcomes are measured. TBI rehabilitation is complex, and the process of unpacking the rehabilitation box to see what it has to offer is no small undertaking. The TBI rehabilitation debate regarding what we know thus far and steps for the future points to prioritizing treatment research models that are effective, efficient, and reflect the values and priorities of participants. With that in mind, CIR is a clear research priority.

\section{Standardizing Clinical Research Through Treatment Manuals}

Progress in developing an evidence base for CIR has been hampered by the diversity of definitions, varied approaches, and lack of systematic, detailed descriptions of actual treatment activities, thereby limiting options for replication, RCTs, and multicenter studies. Standardization of treatment for such an individualized treatment approach as brain injury CIR is onerous. However, similar processes have successfully led to extensive research in an equally complex and individualized arena, cognitivebehavior therapy (CBT) [36-38].

The CBT treatment manual approach has been implemented and researched for many behavioral health conditions, including generalized anxiety disorder [39], social phobia [40], vocational rehabilitation in schizophrenia [41], substance abuse [42], mood disorders [43-44], domestic violence [45], and anger management [46], among others. CBT treatment manuals have also been used in behavioral medicine, providing treatment for medically complicated problems such as erectile dysfunction [47], eating disorders and obesity [48-50], chronic fatigue [51], irritable bowel syndrome [52], chronic pain [53], and tic disorders [54]. Such CBT treatment manuals have even been targeted to specific treatment populations, including prisoners [42], low-income and minority groups [43-44], and persons with developmental disabilities [46]. Thus, the treatment manual model holds significant potential to advance clinical research in TBI CIR, because the approach has both the structure and flexibility to address the many important factors of such an endeavor.

\section{Development and Implementation of TBI Community- Integrated Rehabilitation for Military Personnel}

The valuable clinical research characteristics identified early in DVBIC's history (homogeneity, available records, infrastructure, multisite, outcomes measurement, tracking) [4] provide an optimal foundation for CIR research through VANC, a DVBIC core civilian partner program with a long history of CIR focus and expertise. VANC's Neurobehavioral CIR Pilot Clinical Research Project develops and implements educational and treatment interventions with VANC program participants from the military and veteran populations who have suffered mild, moderate, and severe TBI, primarily from combatrelated IED blast forces and motor vehicle accidents. These military personnel with TBI have benefited from acute medical intervention and acute and/or subacute rehabilitation hospitalization at other DVBIC facilities, and they have progressed to where they hope to benefit from treatment at the VANC residential and day-treatment program aimed at community reentry and focused on the unique needs of military and veteran populations, such as readjustment to civilian life, balancing military and family relationships, risk for posttraumatic stress disorder (PTSD), and other factors. 
The military and veteran program participants at VANC are typically several months post-TBI and have made substantial recovery, yet they still suffer mild-tomoderate neurobehavioral deficits typically associated with frontal and temporal lobe dysfunction and executive dyscontrol. These participants are still in the active stages of recovery and no longer require acute medical intervention, but they may have balance problems, ataxia, coordination impairment, impaired activities of daily living, memory difficulties, attentional problems, fatigue, problematic initiation and motivation, irritability, frustration, depression, sleep disturbance, poor judgment, impulsiveness, anosognosia, organizational problems, speech difficulties, poor anger control and socialization skills, general cognitive dysfunction, and family or work stress, as well as PTSD.

VANC has developed and has been testing the components of a formalized 12-week pilot day program to address most of these issues through education, functional therapeutic interventions, CBT procedures, group therapy and discussions, and individual treatment. The program is divided into 12 standardized educational and group interaction modules, followed by individual and group therapy sessions and functional implementation. Each of the 12 modules will include a detailed manual that facilitates replication, RCTs, multicenter work, treatment component analyses, and eventual dissemination as indicated across the DVBIC, military, and veteran systems and the civilian rehabilitation community at large. Initial module development is based on a review of the scientific literature, clinical judgment and expertise, and initial program participant feedback and historical outcomes. These educational and group sessions modules include-

- Introduction: Exploring the problems and initial evaluations.

- Wellness: Stress, fatigue, pain management, and relaxation.

- Wellness: Coordination, flexibility, exercise, nutrition, and sleep.

- Focusing attention.

- Time management.

- Memory: How to compensate.

- Maximizing memory in functional environments.

- Organizing daily life and daily living skills.

- Problem solving, awareness, judgment, safety, and impulsivity.

- Social interaction: Cognitive and emotional changes (depression, anxiety, irritability, and anger management).
- Social interaction: Assertiveness/picking up the pieces.

- Review and synthesis.

Refinement and implementation of the above sessions/modules will be followed by individual and small group therapy sessions with physical therapy, occupational therapy, speech therapy, cognitive therapy, psychological counseling, and vocational counseling. Work on all the above issues is practiced and enhanced within the broad context of community reentry and VANC's real-life volunteerism, clubhouse membership, supported-work experiences, transportation skill development, community navigation, laundry, shopping, budgeting, banking, and meal preparation. The definitions and descriptions of this enriched environment and therapeutic milieu are articulated in the relevant module treatment manuals. All program content is structured, documented, and developed into a standard manual format to facilitate clinical research and staff training, as well as the transfer and generalization of this program to other settings.

Pre- and postprogram assessments, with measures such as the Scale of Independent Behavior-Revised [55], the Disability Rating Scale [56], the Beck Depression Inventory [57], the Community Integration Questionnaire [58], the Neurobehavioral Rating Scale [59], the Judgment and Safety Screening Inventory [60], the Mayo Portland Adaptability Inventory [12], the Brain Injury Community Rehabilitation Outcome-39 [16], and the European Brain Injury Questionnaire [61], program participant satisfaction scales, and quality-of-life scales, are used for evaluating progress and outcome, both for individual program participant information and further treatment planning, and for assessing programmatic efficacy. Postdischarge follow-up data, including residential and occupational outcomes and participant feedback, are also solicited and will be analyzed for further refinement of the model, treatment manuals, and staff training tools.

\section{CONCLUSIONS}

Military and civilian patients with moderate to severe brain injuries require a continuum of care that involves acute hospitalization and postacute rehabilitation, including community reintegration and hopefully a return to duty and function as productive members of their respective communities. Many treatment models for community reintegration exist; however, the evidence for effectiveness of these programs is limited because of lack of 
standardization of intervention strategies and limited controlled outcome research. By tracking effective approaches to treating servicemen and women who have experienced brain injuries in the course of their duties, VANC hopes to delineate the most cost-effective and standardized strategies for use in military, veteran, and civilian populations. This article describes a manualized TBI rehabilitation pilot program designed to provide community reintegration and assist individuals with TBI to return to duty and work. Such programs are critical if we are to meet the ever-escalating needs of our military, veteran, and civilian populations with TBI.

\section{ACKNOWLEDGMENTS}

This material is the result of work supported with resources and use of facilities at the DVBIC at VANC, under contract W81XWH-07-CV-0089.

The authors have declared that no competing interests exist.

\section{REFERENCES}

1. Langlois JA, Rutland-Brown W, Thomas KE. National Center for Injury Prevention and Control Division of Injury and Disability Outcomes and Programs. Traumatic brain injury in the United States: Emergency department visits, hospitalizations, and deaths. Atlanta (GA): Department of Health and Human Services, Centers for Disease Control and Prevention, Division of Acute Care, Rehabilitation and Disability Prevention, National Center for Injury Prevention and Control; 2004.

2. Thurman DJ. The epidemiology and economics of head trauma. In: Miller LP, Hayes RL, editors. Head trauma therapeutics: Basic, preclinical and clinical aspects. New York (NY): John Wiley and Sons; 2001.

3. Thurman DJ, Alverson C, Dunn KA, Guerrero J, Sniezek JE. Traumatic brain injury in the United States: A public health perspective. J Head Trauma Rehabil. 1999; 14(6):602-15. [PMID: 10671706]

4. Salazar AM, Zitnay GA, Warden DL, Schwab KA. Defense and Veterans Head Injury Program: Background and overview. J Head Trauma Rehabil. 2000;15(5):1081-91. [PMID: 10970929]

5. Henry M. Jackson Foundation for the Advancement of Military Medicine, Inc [homepage on the Internet]. Rockville (MD): HJF; c2007 [updated 2006; cited 20 Dec 2006]. The Defense and Veterans Brain Injury Center-Providing care for soldiers with traumatic brain injury: [about 1 screen]. Available from http://www.hjf.org/research/featureDVBIC.html

6. Warden DL, Salazar AM, Martin EM, Schwab KA, Coyle M, Walter J. A home program of rehabilitation for moderately severe traumatic brain injury patients. The DVHIP Study Group. J Head Trauma Rehabil. 2000;15(5):1092-1102. [PMID: 10970930]

7. Malec JF, Basford JS. Postacute brain injury rehabilitation. Arch Phys Med Rehabil. 1996;77(2):198-207. [PMID: 8607747]

8. Willer B, Button J, Rempal R. Residential and home-based postacute rehabilitation of individuals with traumatic brain injury: A case control study. Arch Phys Med Rehabil. 1999;80(4):399-406. [PMID: 10206601]

9. Wood RL, McCrea JD, Wood LM, Merriman RN. Clinical and cost effectiveness of post-acute neurobehavioral rehabilitation. Brain Inj. 1999;13(2):69-88.

10. Glenn MB, Rotman M, Goldstein R, Selleck EA. Characteristics of residential community integration programs for adults with brain injury. J Head Trauma Rehabil. 2005; 20(5):393-401. [PMID: 16170248]

11. Ben-Yishay Y, Silver SM, Paisetsky E, Rattock J. Relationship between employability and vocational outcome after intensive holistic cognitive rehabilitation. J Head Trauma Rehabil. 1987;2:35-48.

12. Malec JF. Impact of comprehensive day treatment on societal participation for persons with acquired brain injury. Arch Phys Med Rehabil. 2001;82(7):885-95.

[PMID: 11441373]

13. Prigatano GP. Principles of neuropsychological rehabilitation. New York (NY): Oxford University Press; 1999.

14. Vander Laan R, Brandys C, Sullivan I, Lemsky C. Integration through a city-wide brain injury network and best practices project. NeuroRehabilitation. 2001;16(1):17-26. [PMID: 11455100]

15. Minnes P, Carlson P, McColl MA, Nolte ML, Johnston J, Buell K. Community integration: A useful construct, but what does it really mean? Brain Inj. 2003;17(2):149-59.

[PMID: 12519641]

16. Powell J, Heslin J, Greenwood R. Community based rehabilitation after severe traumatic brain injury: A randomised controlled trial. J Neurol Neurosurg Psychiatry. 2002;72(2): 193-202. [PMID: 11796769]

17. Bilbao A, Kennedy C, Chatterji S, Ustun B, Barquero JL, Barth JT. The ICF: Applications of the WHO model of functioning, disability and health to brain injury rehabilitation. NeuroRehabilitation. 2003;18(3):239-50.

[PMID: 14530589]

18. Wood RL, Worthington AD. Outcome in community rehabilitation: Measuring the social impact of disability. Neuropsychol Rehabil. 1999;9(3/4):505-16. 
19. Turner-Stokes L, Disler PB, Nair A, Wade DT. Multidisciplinary rehabilitation for acquired brain injury in adults of working age. Cochrane Database Syst Rev. 2005;(3): CD004170. [PMID: 16034923]

20. Carnevale GJ, Anselmi V, Busichio K, Millis SR. Changes in ratings of caregiver burden following a communitybased behavior management program for persons with traumatic brain injury. J Head Trauma Rehabil. 2002; 17(2):83-95. [PMID: 11909508]

21. Pace GM, Schlund MW, Hazard-Haupt T, Christensen JR, Lashno M, McIver J, Peterson K, Morgan KA. Characteristics and outcomes of a home and community-based neurorehabilitation programme. Brain Inj. 1999;13(7):535-46. [PMID: 10462150]

22. Sander AM, Roebuck TM, Struchen MA, Sherer M, High WM Jr. Long-term maintenance of gains obtained in postacute rehabilitation by persons with traumatic brain injury. J Head Trauma Rehabil. 2001;16(4):356-73. [PMID: 11461658]

23. Coetzer R, Rushe R. Post-acute rehabilitation following traumatic brain injury: Are both early and later improved outcomes possible? Int J Rehabil Res. 2005;28(4):361-63. [PMID: 16319563]

24. Hashimoto K, Okamoto T, Wantanabe S, Ohashi M. Effectiveness of a comprehensive day treatment program for rehabilitation of patients with acquired brain injury in Japan. J Rehabil Med. 2006;38(1):20-25.

[PMID: 16548083]

25. Sarajuuri JM, Kaipio ML, Koskinen SK, Niemela MR, Servo AR, Vilkki JS. Outcome of a comprehensive neurorehabilitation program for patients with traumatic brain injury. Arch Phys Med Rehabil. 2005;86(12):2296-2302. [PMID: 16344026]

26. Tiersky LA, Anselmi V, Johnston MV, Kurtyka J, Roosen E, Schwartz T, Deluca J. A trial of neuropsychological rehabilitation in mild-spectrum traumatic brain injury. Arch Phys Med Rehabil. 2005;86(8):1565-74. [PMID: 16084809]

27. Cicerone KD, Mott T, Azulay J, Friel JC. Community integration and satisfaction with functioning after intensive cognitive rehabilitation for traumatic brain injury. Arch Phys Med Rehabil. 2004;85(6):943-50. [PMID: 15179648]

28. Bowen A, Tennant A, Neumann V, Chamberlain MA. Evaluation of a community-based neuropsychological rehabilitation service for people with traumatic brain injury. NeuroRehabilitation. 1999;13(3):147-55.

29. Bach-y-Rita P. Late postacute neurologic rehabilitation: Neuroscience, engineering, and clinical programs. Arch Phys Med Rehabil. 2003;84(8):1100-8. [PMID: 12917846]

30. Gray DS. Slow-to-recover severe traumatic brain injury: A review of outcomes and rehabilitation effectiveness. Brain Inj. 2000;14(11):1003-14. [PMID: 11104140]
31. High WM Jr, Roebuck-Spencer T, Sander AM, Struchen MA, Sherer M. Early versus later admission to postacute rehabilitation: Impact on functional outcome after traumatic brain injury. Arch Phys Med Rehabil. 2006;87(3): 334-42. [PMID: 16500166]

32. Turner-Stokes L. The evidence for the cost-effectiveness of rehabilitation following acquired brain injury. Clin Med. 2004;4(1):10-12. [PMID: 14998259]

33. Whyte J. Traumatic brain injury rehabilitation: Are there alternatives to randomized clinical trials? Arch Phys Med Rehabil. 2002;83(9):1320-22. [PMID: 12235618]

34. Cicerone KD. Evidence-based practice and the limits of rational rehabilitation. Arch Phys Med Rehabil. 2005; 86(6):1073-74. [PMID: 15954042]

35. Vanderploeg RD, Collins RC, Sigford B, Date E, Schwab K, Warden D. Defense and Veterans Brain Injury Center Veterans Health Administration study planning group. Practical and theoretical considerations in designing rehabilitation trials: The DVBIC cognitive-didactic versus functional-experiential treatment study experience. J Head Trauma Rehabil. 2006;21(2):179-93. [PMID: 16569991]

36. Duncan E, Nicol MM, Ager A. Factors that constitute a good cognitive behavioural treatment manual: A Delphi study. Behav Cog Psychother. 2004;32(2):199-213.

37. Hunsley J, Rumstein-McKean O. Improving psychotherapeutic services via randomized clinical trials, treatment manuals, and component analysis designs. J Clin Psychol. 1999;55(12):1507-17. [PMID: 10855484]

38. Sholomskas DE, Syracuse-Siewert G, Rounsaville BJ, Ball SA, Nuro KF, Carroll KM. We don't train in vain: A dissemination trial of three strategies of training clinicians in cognitive-behavioral therapy. J Consult Clin Psychol. 2005;73(1):106-15. [PMID: 15709837]

39. Linden M, Zubraegel D, Baer T, Franke U, Schlattmann P. Efficacy of cognitive behaviour therapy in generalized anxiety disorders. Results of a controlled trial (Berlin CBTGAD Study). Psychother Pscyhosom. 2005;74(1):36-42. [PMID: 15627855]

40. Klinger E, Bouchards S, Legeron P, Roy S, Lauer F, Chemin I, Nugues P. Virtual reality therapy versus cognitive behavior therapy for social phobia: A preliminary controlled study. Cyberpsychol Behav. 2005;8(1):76-88. [PMID: 15738695]

41. Davis LW, Lysaker PH, Lancaster RS, Bryson GJ, Bell MD. The Indianapolis Vocational Intervention Program: A cognitive behavioral approach to addressing rehabilitation issues in schizophrenia. J Rehabil Res Dev. 2005;42(1):35-45. [PMID: 15742248]

42. Malinowski A. What works with substance users in prison? J Subst Abuse. 2003;8(4):223-33.

43. Miranda J, Chung JY, Green BL, Krupnick J, Siddique J, Revicki DA, Belin T. Treating depression in predominantly 
low-income young minority women: A randomized controlled trial. JAMA. 2003;290(1):57-65. [PMID: 12837712]

44. Munoz RF, Mendelson T. Toward evidence-based interventions for diverse populations: The San Francisco General Hospital prevention and treatment manuals. J Consult Clin Psychol. 2005;73(5):790-99. [PMID: 16287379]

45. Stith SM, Rosen KH, McCollum EE. Developing a manualized couples treatment for domestic violence. J Marital Fam Ther. 2002;28(1):21-26.

46. Taylor JL, Novaco RW. Anger treatment for people with developmental disabilities: A theory, evidence, and manual based approach. Hoboken (NJ): Wiley; 2005.

47. Bach AK, Barlow DH, Wincze JP. The enhancing effects of manualized treatment for erectile dysfunction among men using sildenafil: A preliminary investigation. Behav Ther. 2004;35(1):55-74.

48. Ball J, Mitchell P. A randomized controlled study of cognitive behavior therapy and behavioral family therapy for anorexia nervosa patients. Eat Disord. 2004;12(4):303-14. [PMID: 16864523]

49. Cooper Z, Fairburn CG, Hawker DM. Cognitive-behavioral treatment of obesity: A clinician's guide. New York (NY): Guilford Press; 2003.

50. Jeffrey DB, Christensen ER, Pappas JP. Developing a behavioral program and therapist manual for the treatment of obesity. J Am Coll Health Assoc. 1973;21(5):455-59. [PMID: 4711915]

51. Bazelmans E, Prins JB, Hoogveld S, Bleijenberg G. Manualbased cognitive behaviour therapy for chronic fatigue syndrome: Therapists' adherence and perceptions. Cogn Behav Ther. 2004;33(3):143-50. [PMID: 15471384]

52. Blanchard EB. Irritable bowel syndrome: Psychosocial assessment and treatment. Washington (DC): American Psychological Association; 2001.

53. Morley S, Shapiro DA, Biggs J. Developing a treatment manual for attention management in chronic pain. Cogn Behav Ther. 2004;33(1):1-11. [PMID: 15224623]
54. O'Connor KP. Cognitive-behavioral management of tic disorders. Hoboken (NJ): John Wiley \& Sons; 2005.

55. Ipsen SM. Scales of independent behavior Woodcock Johnson Educational Battery part four. Educ Train Ment Ret. 1986;21(2):153-54.

56. Rappaport M, Hall KM, Hopkins K, Belleza T, Cope DN. Disability rating scale for severe head trauma: Coma to community. Arch Phys Med Rehabil. 1982;63(3):118-23. [PMID: 7073452]

57. Beck AT, Ward CH, Mendelson M, Mock J, Erbaugh J. An inventory for measuring depression. Arch Gen Psychiatry. 1961;4:561-71. [PMID: 13688369]

58. Corrigan JD, Deming R. Psychometric characteristics of the Community Integration Questionnaire: Replication and extension. J Head Trauma Rehabil. 1995;10(4):41-53.

59. Levin HS, High WM, Goethe KE, Sisson RA, Overall JE, Rhoades HM, Eisenberg HM, Kalisky Z, Gary HE. The neurobehavioral rating scale: Assessment of the behavioural sequelae of head injury by the clinician. J Neurol Neurosurg Psychiatry. 1987;50(2):183-93.

60. Kreutzer JS, West DD, Marwitz J. Judgment and safety screening inventory administration manual. Richmond (VA): National Resource Center for Traumatic Brain Injury; 2001. p. 56.

61. Deloche G, Dellatolas G, Christensen AL. The European Brain Injury Questionnaire: Patients' and families' subjective evaluation of brain-injured patients' current and prior to injury difficulties. In: Christensen AL, Uzzell BP, editors. International handbook of neuropsychological rehabilitation. New York (NY): Kluwer Academic Publishers; 2000. p. 83-95.

Submitted for publication December 20, 2006. Accepted in revised form August 29, 2007. 